\title{
STUDI VARIASI PERMUKAAN LAUT JAWA DAN LAUT CHINA SELATAN TAHUN 2002-2019 MENGGUNAKAN DATA ALTIMETRI JASON
}

\author{
Fiamanati Sulaiha1, Eko Yuli Handoko², Yuwono ${ }^{3}$ \\ 1,2,3Program Studi Teknik Geomatika FTSLK-ITS, Kampus ITS Sukolilo, Surabaya, 60111 \\ e-mail: 1fiamanatis@gmail.com, ${ }^{2}$ eyhandoko@gmail.com, ${ }^{3}$ yuwono@geodesy.its.ac.id
}

\begin{abstract}
Abstrak
Fenomena pemanasan global dapat menimbulkan adanya ekspansi termal dan variasi massa air yang mengakibatkan pencairan gletser, lapisan es di kutub dan perubahan rata-rata permukaan laut global. Efek ini memiliki dampak yang penting pada sosial ekonomi, infrastruktur dan lingkungan, yang menyebabkan hilangnya tanah disekitar daerah pesisir pantai dimana lebih dari pada $10 \%$ penduduk dunia hidup. Sejak akhir abad ke-18, perubahan kedudukan air laut diamati dari stasiun pasang surut di sepanjang garis pantai. Namun, pengamatan stasiun pasang surut memiliki keterbatasan dalam jumlah, distribusi, dan jangkauannya, serta adanya pengaruh land subsidence. Oleh karena itu, penelitian ini menganalisis variasi permukaan laut di Laut Jawa dan Laut China Selatan selama periode 2002-2019 menggunakan data pengamatan misi referensi satelit altimetri, yaitu Jason 1, Jason 2, dan Jason 3. Variasi permukaan laut yang diamati menunjukkan laju kenaikan muka air laut sebesar 4,1 mm/tahun, dimana kecepatan tinggi terjadi di sekitar Laut Jawa bagian Utara atau Selatan yang memiliki nilai 7-9 mm/tahun. Sehingga berdasarkan hasil tersebut dapat dilakukan perencanaan pra-kejadian terhadap dampak dari kenaikan muka air laut yang akan mendatang.
\end{abstract}

Kata Kunci: Altimetri, Intercalibrated, Sea Level Anomaly, Trend.

\begin{abstract}
The phenomenon of global warming can lead to thermal exposure and variations in water masses that require melting glaciers, polar ice sheets and changes in global sea level averages. This effect has an important impact on socio-economic, infrastructure and environment, which causes land changes of around $10 \%$ of the world's population. Since the end of the 18th century, changes in the position of open air from tidal stations along the coastline. However, observation of tide stations has limitations in number, distribution, and coverage, as well as variations in land subsidence. Therefore, this study analyzes sea surface variations in the Java Sea and the South China Sea during the period 2002-2019 using altimetry satellite reference mission data, namely Jason 1, Jason 2, and Jason 3. Sea level variations that need to be studied increase sea air by $4.1 \mathrm{~mm} /$ year, where high speeds occur around the North or South Java Sea which has a value of 7-9 $\mathrm{mm} /$ year. So based on these results pre-event planning can be carried out on the impact of the upcoming sea level rise.
\end{abstract}

Keywords: Altimetry, Intercalibrated, Sea Level Anomaly, Trend. 


\section{PENDAHULUAN}

Fenomena pemanasan global diperoleh dari peningkatan emisi gas rumah kaca secara berlebihan di atmosfer melalui penggunaan bahan bakar fosil, deforestasi dan aktivitas manusia lainnya, telah berdampak negatif bagi keberlanjutan ekosistem pesisir dan lautan. Fenomena tersebut menimbulkan adanya ekspansi termal dan variasi massa air yang mengakibatkan pencairan gletser, lapisan es di kutub dan perubahan rata-rata permukaan laut global (Cazenave A, 2012).

Pengamatan perubahan kedudukan air laut pertama dilakukan dengan memantau melalui stasiun pasang-surut pada abad ke-18. Pengamatan stasiun pasang surut dilakukan disepanjang garis pantai (Church dan White, 2011). Namun, pengamatan stasiun pasang surut tersebut memiliki keterbatasan dalam jumlah, distribusi dan jangkauan. Kemudian diperoleh variasi rata-rata permukaan laut global antar tahunan hingga 2-3mm yang dimonitor menggunakan data altimetri satelit multi-misi selama Rentang waktu 1993-2010 (Ablain et al, 2015). Sedangkan menurut laporan IPCC 2014 bahwa rata-rata suhu permukaan global meningkat $0,3-0,6^{\circ} \mathrm{C}$ sejak akhir abad 19 (Church et al, 2013) dan sampai tahun 2100 suhu bumi diperkirakan akan naik sekitar $1,4-5,8^{\circ} \mathrm{C}$ (Dahuri, 2002). Naiknya suhu permukaan global menyebabkan mencairnya es di kutub utara dan selatan bumi sehingga berbanding lurus dengan kenaikan muka air laut. Efek ini memiliki dampak yang penting pada sosial ekonomi nasional, infrastruktur dan lingkungan, yang menyebabkan hilangnya tanah disekitar daerah pesisir pantai dimana lebih dari pada $10 \%$ penduduk dunia hidup (Handoko et al, 2017).

Sejak kehadiran teknologi satelit altimetri yang dapat melakukan pengamatan dengan mengukur jarak antara satelit dan permukaan laut, diketahui ketinggian satelit altimetri diatas bidang ellipsoid maka ketinggian permukaan laut di atas bidang ellipsoid dapat dihitung (Andersen dan Scharroo, 2011). Salah satunya Sea level anomaly (SLA) merupakan tinggi muka laut yang tereferensi pada bidang Mean Sea Surface, dimana efek instrumen, efek jarak, dan efek dinamisnya yaitu gelombang laut, pasang surut dan pengaruh tekanan atmosfer sudah dihilangkan. Para ilmuwan telah mengungkapkan signifikan variasi tahunan permukaan laut di Laut China Selatan dengan satelit data altimeter selama lebih dari 13 tahun (Cheng, $X$ dan Qi, Y, 2007). Hasilnya menunjukkan bahwa perubahan termal dari lapisan atas SCS memiliki kontribusi signifikan terhadap variasi permukaan laut.

Penelitian ini bertujuan untuk menganalisis variasi kenaikan muka air Laut Jawa dan Laut China Selatan selama 17 tahun yaitu tahun 2002-2019 berdasarkan data pengamatan satelit altimetri Jason-1, Jason-2 dan Jason-3. Dengan demikian didapatkan hasil yang mampu menggambarkan variabilitas permukaan laut di lokasi tersebut.

\section{METODOLOGI PENELITIAN}

\section{Data dan Peralatan}

Data yang digunakan dalam penelitian ini adalah data sekunder dapat diunduh diwebsite resmi RADS (Radar Altimeter Database System). Berikut adalah detail mengenai data sekunder tersebut.

a. Data RADS Jason-1 Periode 2002-2009

b. Data RADS Jason-2 Periode 2008-2016

c. Data RADS Jason-3 Periode 2016-2019

Ketiga data RADS tersebut yang akan digunakan dalam perhitungan SLA Pada trend kenaikan muka air laut.

Peralatan yang digunakan dalam penelitian ini adalah sebagi berikut.

a. Perangkat lunak MATLAB R2015a 

b. Perangkat lunak $R$
c. Grapher
d. Surfer
e. Microsoft Excel

\section{Lokasi Penelitian}

Lokasi penelitian ini berada di wilayah perairan Indonesia bagian barat yaitu Laut Jawa dan Laut China Selatan yang terletak pada koordinat $8^{\circ} \mathrm{LS}$ $-8^{\circ} \mathrm{LU}$ dan $102^{\circ} \mathrm{BT}-118^{\circ} \mathrm{BT}$.

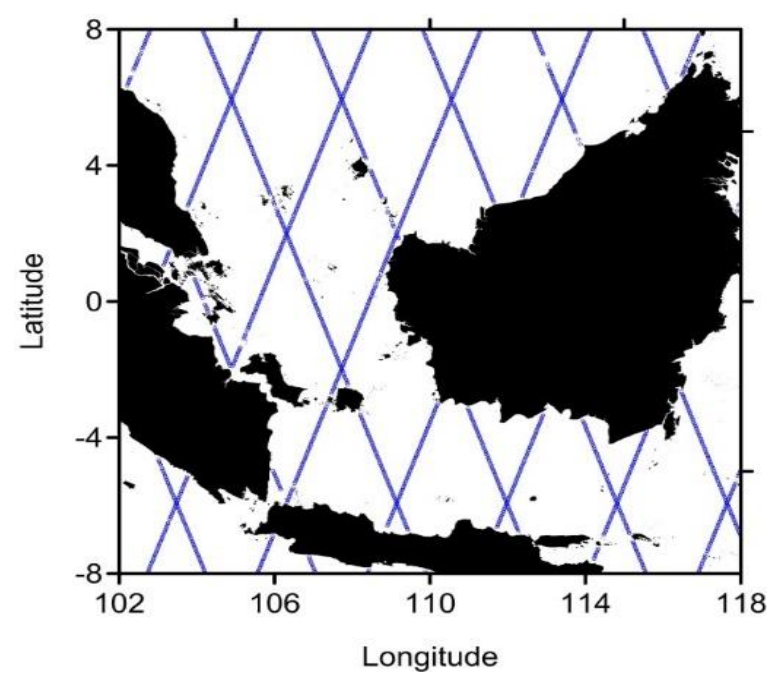

Gambar 1. Lokasi Penelitian

\section{Metodologi}

- Pengumpulan Data

Pengumpulan data sekunder berupa parameter koreksi data satelit altimetri serta nilai pengamatan satelit altimetri Jason 1 , Jason 2 dan Jason 3 yang meliputi range dan altitude satelit dari referensi ellipsoid. Set data berformat NetCDF yang nantinya akan diterjemahkan menggunakan bahasa MATLAB R2015a.

- Pengolahan Data

1. Perhitungan SLA

Proses pengolahan Sea level anomaly (SLA) dihitung menggunakan rumus berikut:

$$
\mathrm{h}_{\mathrm{SLA}}=\mathrm{H}-\mathrm{R}_{\mathrm{obs}}-\Delta \mathrm{RGeo}_{\text {corrs }} \mathrm{H}-\mathrm{h}_{\mathrm{MSS}}
$$

Keterangan:

h_SLA= Sea Level Anomaly (m)

$\mathrm{H} \quad$ = tinggi satelit diatas ellipsoid $(\mathrm{m})$

$$
\begin{aligned}
& \text { R_obs = jarak observasi antara } \\
& \text { Antenna Altimeter } \\
& \text { satelit dengan } \\
& \text { permukaan air } \\
& \text { sementara }(\mathrm{m})
\end{aligned}
$$

Kemudian dilakukan kontrol kualitas dalam range -5 hingga 5 meter terhadap hasil SLA. Hal ini dilakukan untuk menghilangkan data yang outlier. Apabila nilai memenuhi akurasi maksimum dari masing-masing kualitas oleh Jason-1, Jason 2, dan Jason 3 maka akan dilanjutkan ke proses berikutnya. Apabila tidak memenuhi berarti perlu diulang kembali prosesnya untuk data yang outlier.

\section{Rata-rata SLA}

Nilai SLA dirata-rata berdasarkan pembobotan lintang karena sudut inklinasi satelit ketika mengelilingi bumi menyebabkan perbedaan yang lama. Cycle yang bertampalan tersebut terdapat bias karena masing-masing satelit memiliki koreksi instrumen dan model sendiri.

\section{Intercalibrated Tandom Mission}

Pada proses pengolahan data tahap ini, dilakukan untuk menghilangkan biar antar satelit. Selanjutnya yang harus dilakukan adalah menghitung bias antar data tandem atau yang bertampalan 
dengan cara manual menggunakan Microsoft Excel.

\section{Penguraian Time Series}

Diawali dengan data SLA yang telah terkoreksi, kemudian dilakukan penguraian time series ke berbagai komponen yaitu seasonal, trend-cycle, dan remainder. Penguraian Time Seies ini menggunakan metode STL (A SeasonalTrend Decomposition Procedure Based on Regression). Dekomposisi Time Series dikerjakan menggunakan program $\mathrm{R}$ sehingga didapatkan trend SLA. Setelah didapatkan nilai trend maka selanjutnya dilakukan perhitungan persamaan regresi dengan variabel $\mathrm{X}$ adalah waktu.

\section{Gridding SLA}

Kemudian proses gridding dilakukan dengan tujuan untuk membuat peta persebaran trend SLA, sekaligus mengisi kekosongan data terhadap nilai lintangbujur, agar didapatkan hasil pemodelan yang lebih baik. Gridding data dilakukan untuk menampilkan perubahan berupa peta kontur warna 2D serta mendapatkan gambar visualisasinya. Gridding SLA dilakukan dengan ukuran $3^{\circ} \times 3^{\circ}$, sebelumnya harus dihitung terlebih dahulu untuk setiap siklus ( 10 hari) untuk mendistribusikan pengukuran yang sama di seluruh permukaan lautan. Pemilihan ukuran grid berdasarkan jarak antar pass pada satelit Jason.

- Analisis

1. Analisis yang dilakukan bertujuan untuk mengetahui tingkat kenaikan SLA. Garis trend secara linier bisa didapatkan dengan melakukan regresi linier.

$$
Y=a X+b
$$

Keterengan:

$\mathrm{Y}=$ Variabel terikat (SLA)

$a=$ Koefisien regresi

$\mathrm{b}=$ Intersep

$\mathrm{X}=$ Variabel bebas (waktu)

\section{HASIL DAN PEMBAHASAN}

\section{Hasil Perhitungan Sea Level Anomaly}

Nilai SLA yang dihitung menggunakan perangkat lunak MATLAB ini merupakan tinggi permukaan laut yang tereferensi pada bidang geoid atau MSS, dimana efek pengaruh atmosfer sudah dihilangkan.

\begin{tabular}{cccccc}
\multicolumn{6}{c}{ Tabel 1. Hasil Perhitungan Sea Level Anomaly } \\
\hline Cyc & Pass & MJD & Lat & Lon & SLA \\
\hline 1 & 229 & 52298,13 & $-7,993$ & 105,5 & $-0,110$ \\
1 & 229 & 52298,13 & $-7,943$ & 105,5 & $-0,140$ \\
1 & 229 & 52298,13 & $-7,849$ & 105,5 & $-0,103$ \\
1 & 229 & 52298,13 & $-7,844$ & 105,6 & $-0,110$ \\
1 & 229 & 52298,13 & $-7,794$ & 105,6 & $-0,102$ \\
1 & 229 & 52298,13 & $-7,744$ & 105,6 & $-0,115$ \\
1 & 229 & 52298,13 & $-7,694$ & 105,6 & $-0,123$ \\
1 & 229 & 52298,13 & $-7,644$ & 105,6 & $-0,061$ \\
1 & 229 & 52298,13 & $-7,594$ & 105,6 & $-0,047$ \\
1 & 229 & 52298,13 & $-7,544$ & 105,7 & $-0,025$ \\
1 & 229 & 52298,13 & $-7,498$ & 105,7 & $-0,058$ \\
1 & 229 & 52298,13 & $-7,444$ & 105,7 & $-0,032$ \\
1 & 229 & 52298,13 & $-7,394$ & 105,7 & $-0,002$ \\
1 & 229 & 52298,13 & $-7,345$ & 105,7 & $-0,001$ \\
1 & 229 & 52298,13 & $-7,295$ & 105,8 & $-0,028$ \\
\hline \multicolumn{7}{c}{}
\end{tabular}

Setelah dilakukan koreksi akan didapatkan nilai Sea Level Anomaly pada masingmasing titik disepanjang lintasan orbit satelit Jason-1, Jason-2 dan Jason-3. Nilainya dapat dikelompokkan pada tiap cycle dan pass. Rincian jumlah cycle masing-masing satelit adalah sebagai berikut:

$\begin{array}{ll}\text { Jason } 1 & =259 \text { cycle } \\ \text { Jason } 2 & =303 \text { cycle } \\ \text { Jason } 3 & =108 \text { cycle }\end{array}$

Pada total jumlah data satelit tersebut, terdapat beberapa data yang hilang antara lain pada Jason-1 seharusnya berjumlah 259 cycle, namun 3 cycle yaitu c000 dan c178 tidak tersedia dari awal data didownload serta c243 tidak tersedia setelah dilakukan proses dilokasi penelitian ini. Total jumlah data Jason-2 seharusnya 303 cycle, namun 2 cycle yaitu c175 dan c191 tidak tersedia setelah dilakukan proses 
dilokasi penelitian. Total jumlah data Jason 3, 108 cycle yang semua datanya sudah lengkap dan sesuai.

\section{Hasil Perhitungan Rata-rata SLA}

Rata-rata dihitung dengan pembobotan berdasarkan latitude, berikut adalah salah satu hari rata-rata per cycle perhitungannya.

\begin{tabular}{cccc}
\multicolumn{4}{c}{ Tabel 2. Hasil Perhitungan Rata-rata SLA } \\
\hline Cyc & MJD & YYF & Mean_SLA \\
\hline 1 & 52294,5 & 2002,0543 & 25,25413 \\
2 & 52304,4 & 2002,0806 & 63,3198 \\
3 & 52314,17 & 2002,1073 & 55,0117 \\
4 & 52324,08 & 2002,1345 & 79,4711 \\
5 & 52333.74 & 2002,1609 & 41,8813 \\
6 & 52343.83 & 2002,1886 & 28,4958 \\
7 & 52353.76 & 2002,2158 & $-25,1505$ \\
8 & 52363.73 & 2002,2431 & $-23,7013$ \\
9 & 52373.73 & 2002,2705 & $-7,0092$ \\
10 & 52383.57 & 2002,2975 & 15,5656 \\
11 & 52393.66 & 2002,3251 & 13,6856 \\
12 & 52403.26 & 2002,3514 & 11,1246 \\
13 & 52413.57 & 2002,3797 & 30,9963 \\
14 & 52423.33 & 2002,4064 & 59,6781 \\
15 & 52433.22 & 2002,4335 & 26,12 \\
\hline
\end{tabular}

Berdasarkan pada tabel diatas menunjukkan bahwa rata-rata sea level anomaly di Laut Jawa dan Laut China Selatan hasil pengamatan Jason 1 berada dalam range -81,8 $\mathrm{mm}$ hingga 251,9 mm, Jason 2 berada dalam range $-59 \mathrm{~mm}$ hingga $219,3 \mathrm{~mm}$, dan Jason 3 berada dalam range $37 \mathrm{~mm}$ hingga 282,5 mm. Rata-rata setiap cycle dibuat grafik untuk mengetahui tandem mission. Tandem mision terjadi karena adanya pengambilan data oleh 2 satelit dalam periode waktu yang sama dengan jalur yang sama. Berikut adalah grafik yang menunjukkan adanya tandem mission 3 misi satelit altimetri yang digunakan pada penelitian ini.

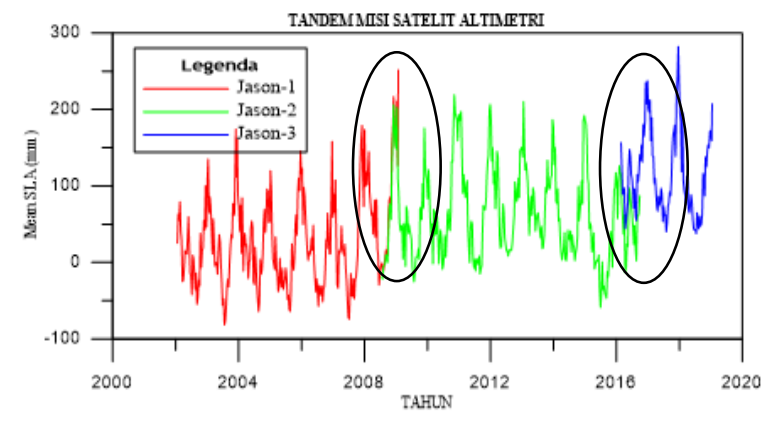

Gambar 2. Tandem Misi Satelit Altimetri

\section{Hasil Perhitungan Bias}

Nilai bias antara satelit Jason-1 dengan Jason-2 adalah 35,729 mm, nilai bias antara Jason 2 dan Jason 3 adalah 41,924 mm. Setelah dilakukan intercalibrated, nilai SLA dari Januari 2002 sampai Januari 2019 ditunjukkan pada Gambar 3.

Setelah dikoreksi bias antar satelit, data yang digunakan harus difilter. Data SLA pada range tandem mission yang digunakan hanya setengah saja masing-masing satelit, misal data SLA Jason-1 yang digunakan adalah cycle 1-249, Jason-2 adalah cycle 11-290, Jason-3 adalah cycle 11-108. Hasil SLA terkoreksi dapat dilihat pada gambar dibawah ini, bahwa lompatan data sudah lebih smooth.

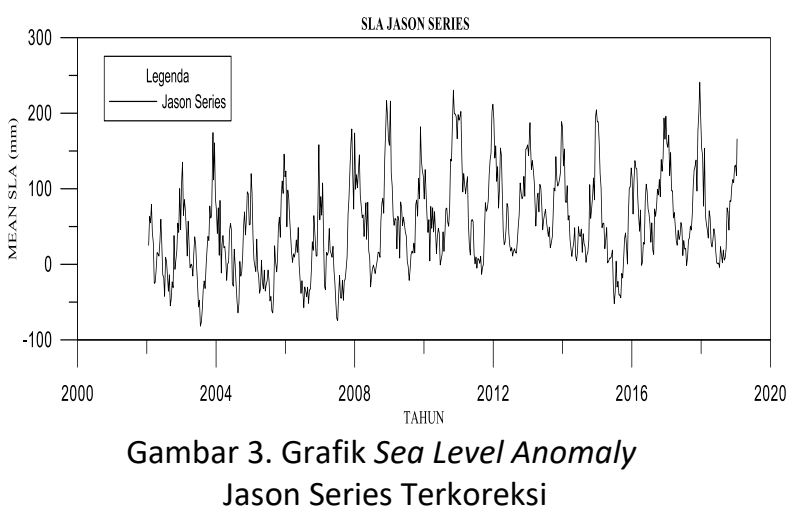

\section{Hasil Pengolahan Time Series}

Setelah dilakukan STL decomposition di R, didapatkan grafik seluruh komponen sebagai berikut:

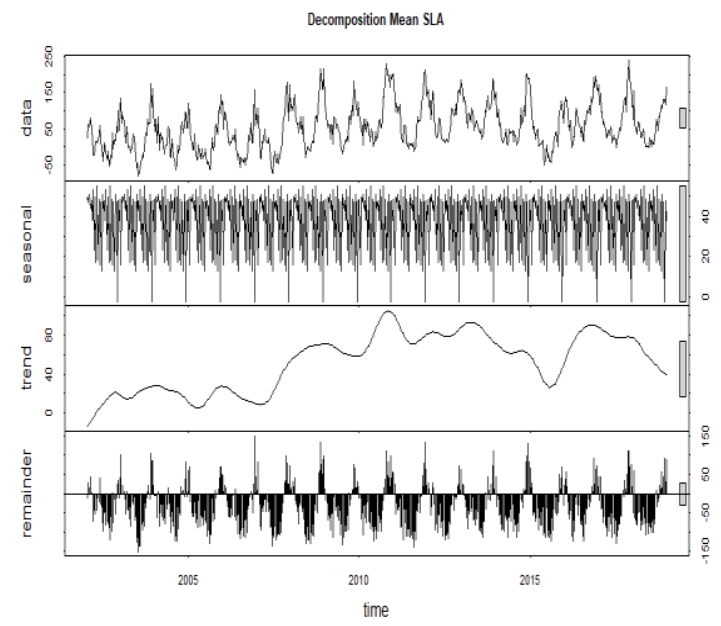

Gambar 4. Time Series Decomposition 


\section{Analisis Regresi Linier}

Hasil trend dari STL decomposition ditunjukkan pada Gambar 5. Berdasarkan trend yang menggunakan nilai SLA-ERA diketahui bahwa nilai minimum SLA terjadi pada bulan Maret tahun 2005 yaitu $-13,8 \mathrm{~mm}$ dan nilai SLA maksimum terjadi pada bulan Maret tahun 2010 yaitu 105,4 $\mathrm{mm}$ dengan hasil persamaan dari regresi linier adalah $y=4,1 x-2857,5$ diketahui bahwa trend linier bernilai positif dari gradien garis kearah kanan.

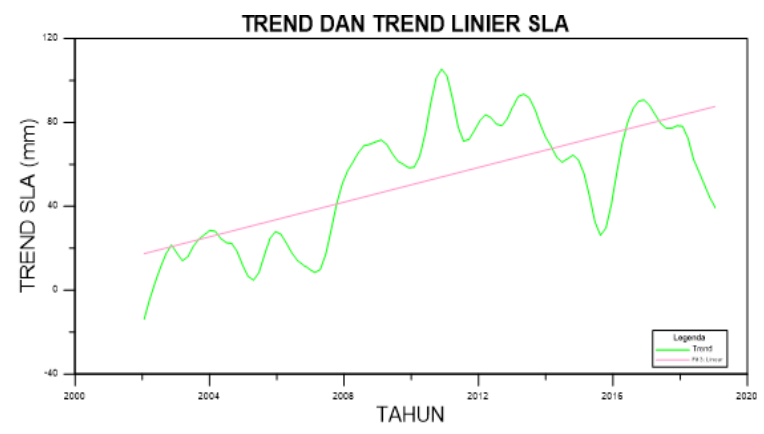

Gambar 5. Grafik Trend SLA

\section{Gridding SLA Tiap Cycle}

Gridding dilakukan dengan metode ( $z=$ mean) dan ukuran grid yang digunakan adalah $3^{\circ} \mathrm{x}$ $3^{\circ}$. Kemudian dihitung nilai SLA dari tiap titik grid untuk semua cycle. Batas wilayah yang digunakan adalah $8^{\circ} \mathrm{LS}-8^{\circ} \mathrm{LU}$ dan $102^{\circ} \mathrm{BT}-$ $118^{\circ}$ BT maka ukuran gridding disesuaikan dengan sumber data yaitu jarak antar jalur dalam satelit altimetri adalah $315 \mathrm{~km}\left( \pm 3^{\circ}\right)$. Grid dihitung setiap cycle dengan format akhir data (.gdr).

Berdasarkan hasil perhitungan SLA disetiap titik didapatkan bahwa nilai SLA cenderung tinggi di perairan bagian selatan. Gambaran variasi kenaikan muka air laut secara menyeluruh di Laut Jawa dan Laut China Selatan dapat dilihat pada gambar 4.13. Sebaran SLA menunjukkan rentang nilai 5 hingga $9 \mathrm{~mm} /$ tahun yang digambarkan dari warna kuning hingga merah. Semakin merah warnanya berarti kecepatannya semakin tinggi, sedangkan semakin kuning berarti kecepatannya semakin mendekati nol.

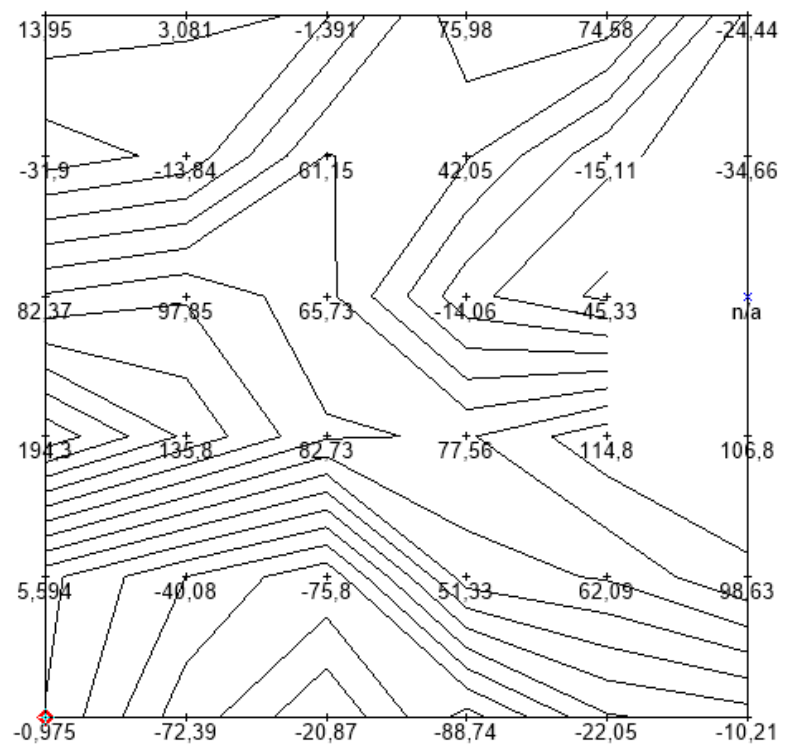

Gambar 6. Hasil Gridding SLA 1 Cycle

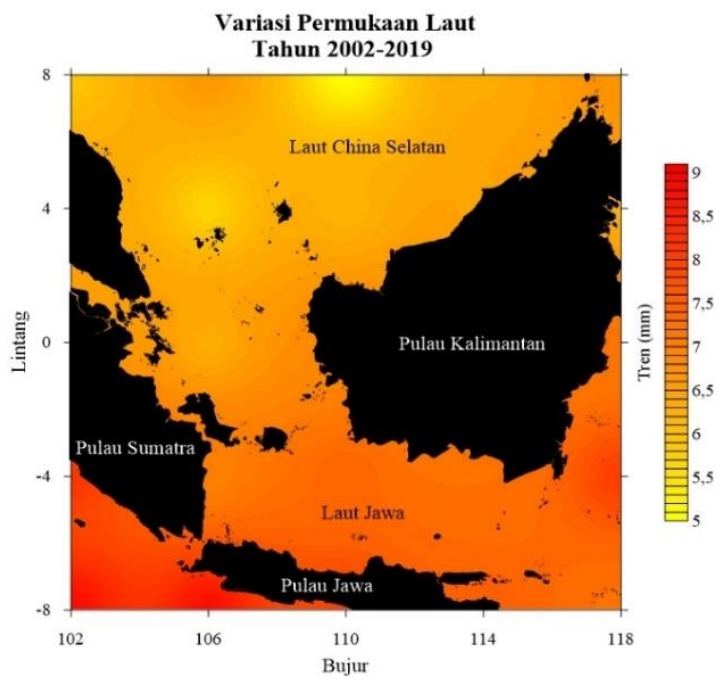

Gambar 7. Peta Variasi Permukaan Laut di Laut Jawa dan Laut China Selatan

\section{KESIMPULAN}

Berdasarkan analisis dari hasil pengolahan data altimetri menggunakan Jason Series, variasi permukaan laut selama periode 2002-2019 yang diamati menunjukkan bahwa SLA naik didaerah Laut Jawa bagian utara dan selatan, sedangkan 
SLA turun didaerah Laut China Selatan. Kenaikan permukaan Laut yang diperoleh sebesar 4,1 $\mathrm{mm} /$ tahun. Oleh karena itu, pulau-pulau kecil di sekitar wilayah memerlukan perhatian khusus agar tidak sampai terjadi penenggalaman pulau dan dampak-dampak lainnya.

Penggunaan Data tambahan seperti data stasiun pasang surut dapat melengkapi area-area pesisir yang tidak tercakup oleh data altimetri dan pengolahan Data menggunakan satelit altmetri multi misi ini dapat ditingkatkan lebih baik lagi terhadap pengaruh kejadian akibat fenomena pemanasan global lainnya.

\section{UCAPAN TERIMA KASIH}

Penulis mengucapkan terima kasih kepada NOAA selaku pihak pengelola RADS (Radar Altimetry Database System) sebagai sumber data yang digunakan dalam penelitian ini.

\section{DAFTAR PUSTAKA}

Ablain, M., Cazenave, A., Larnicol, G., dan Balmaseda, M. 2015. "Improved sea level record over the satellite altimetry era (1993-2010) from the Climate Change Initiative project". Ocean Science, 67-82.Revit, 2018.

Andersen, O. B., dan Scharroo, R. 2011. "Range and geophysical corrections in coastal regions: And implications for mean sea surface determination". Dalam S. Vignudelli, A. G. Kostianoy, P. Cipollini, dan J. Benveniste, Coastal Altimetry (hal. 103-145). Berlin: Springe.

Cazenave, A., Lombard, A., dan Llovel, W. 2008. "Present-day sea level rise: a synthesis". Computation Rendus Geosience, 761770. Heywood, D.I., Cornelius, S.C. \& Carver, S.J. 2011. An Introduction to Geographical Information Systems. Fourth edn. London: Pearson Prentice Hall.

Cheng, Xuhua and Yiquan Qi. 2007. "Trends of Sea Level Variations in the South China Sea from Merged Altimetry Data". Global and Planetary Change 57(3-4):371-82.

Church, J. A., and N. J. White. "Sea-level rise from the late 19th to the early 21st century." Surv. Geophys, 2011: 585-602.Moussa, W. 2014. Integration of Digital Photogrammetry and Terrestrial Laser Scanning for Cultural Heritage Data Recording. PhD Thesis Proposal. German: University of Stuttgart.

Dahuri, R., J. Rais, S. P. Ginting, and M. J. Sitepu. Pengelolaan SUmber Daya Pesisir dan Lautan secara Terpadu. Jakarta: Balai Pustaka, 2008.Trieb, P. B. \& Kilpatrick, D. 2004. Digital Close-range Stereophotogrammetry for Heritage Recording. RCI Incorporation.

Handoko, E. Y., Fernandes, M. J., \& Lazaro, C. 2017. "Assessment of Altimetric Range and Geophysical Corrections and Mean Sea Surface Models-Impacts on Sea Level Variability around Indonesia Seas". Remote Sens, 102. 